\title{
Dari Inpres Moratorium Sawit Hingga Kebijakan Tata Kelola Industri Sawit Presiden Jokowi: Studi Kasus Penerbitan SK Pelepasan Kawasan Hutan PT Hardaya Inti Plantations di Buol, Sulawesi Tengah
}

\author{
Adrianus Eryan ${ }^{1}$
}

\begin{abstract}
Abstrak
Pada September 2018, Presiden Jokowi menerbitkan Inpres No. 8 Tahun 2018 tentang Penundaan dan Evaluasi Perizinan Perkebunan Kelapa Sawit serta Peningkatan Produktivitas Perkebunan Kelapa Sawit (Inpres Moratorium Sawit). Namun, hanya dua bulan berselang, Menteri Lingkungan Hidup dan Kehutanan menerbitkan SK Pelepasan Kawasan Hutan untuk kebun sawit seluas 9.964 hektare di Kabupaten Buol, Sulawesi Tengah, kepada PT Hardaya Inti Plantations (PT HIP). Keputusan ini memicu kontroversi dan protes dari berbagai kalangan, dari Bupati Buol, Komisi Pemberantasan Korupsi (KPK), hingga masyarakat sipil. Berbagai kajian menyatakan bahwa penerbitan SK Pelepasan Kawasan Hutan tersebut melanggar Inpres Moratorium Sawit. Tulisan ini hendak membahas penerbitan SK tersebut secara induktif, dimulai dari proses penerbitannya hingga melihat lebih jauh gambaran kebijakan tata kelola industri sawit di era Presiden Jokowi, baik dari segi teori, legislasi, hingga studi kasus PT HIP. Metode penelitian yang digunakan adalah penelitian yuridis normatif dengan melihat kesesuaian studi kasus dengan peraturan perundang-undangan serta kebijakan yang melandasinya.
\end{abstract}

Kata kunci: Inpres moratorium sawit, tata kelola sawit, Jokowi

\section{Abstract}

In September 2018, President Jokowi enacted Presidential Instruction No. 8 of 2018 concerning the Postponement and Evaluation of Licensing of Palm Oil Plantations and Increasing Productivity of Oil Palm Plantations (Inpres Moratorium Sawit). However, two months after its enactment, the Minister of Environment and Forestry issued a Decree of the Release of Forest Areas for an area of 9.964 hectares of oil palm plantation in Buol District, Central Sulawesi, to PT Hardaya Inti Plantations (PT HIP). This decision sparked controversy and protests from various groups, from the Regent of Buol, the Corruption Eradication Commission (KPK), to civil society. Various studies state that the issuance of the Decree on the Release of Forest Areas violates the Inpres Moratorium Sawit. This paper aims to discuss the issuance of the decree inductively, starting from the issuance process to looking further at the governance policies at the palm oil industry in the era of President Jokowi, both in terms of theory, legislation, and case studies used which is PT HIP. The research method used in this paper is normative juridical

\footnotetext{
${ }^{1}$ Penulis merupakan peneliti dari Divisi Tata Kelola Hutan dan Lahan di Indonesian Center for Environmental Law (ICEL).
} 
research by looking at the suitability of case studies with legislation and policies that underlie them.

Keywords: Presidential Instruction of palm oil moratorium, palm oil governance, Jokowi

\section{Pendahuluan}

Pada tanggal 19 September 2018, penyelamatan hutan dan perbaikan tata kelola perkebunan sawit Indonesia mendapat secercah harapan baru ketika Presiden Joko Widodo atau Jokowi mengeluarkan Instruksi Presiden No. 8 Tahun 2018 tentang Penundaan dan Evaluasi Perizinan Perkebunan Kelapa Sawit serta Peningkatan Produktivitas Perkebunan Kelapa Sawit yang berlaku selama 3 tahun hingga 19 September 2021 (selanjutnya disebut dengan Inpres Moratorium Sawit). Instruksi ini diantaranya memandatkan kepada Menteri Lingkungan Hidup dan Kehutanan untuk menunda pelepasan atau tukar menukar kawasan hutan untuk perkebunan kelapa sawit. ${ }^{2}$

Namun, hanya dua bulan setelah Inpres Moratorium Sawit diterbitkan, yakni pada tanggal 23 November 2018, Menteri Lingkungan Hidup dan Kehutanan (MenLHK) menerbitkan Surat Keputusan Pelepasan Kawasan Hutan untuk kebun sawit seluas 9.964 hektare di Kabupaten Buol, Sulawesi Tengah mela- lui Surat Keputusan Menteri Lingkungan Hidup dan Kehutanan No. SK.517/ MENLHK/SETJEN/PLA/2/11/2018 (selanjutnya disebut dengan SK MenLHK 517/2018), kepada PT Hardaya Inti Plantations (selanjutnya disebut dengan PT HIP).

Keputusan tersebut kemudian menimbulkan protes keras dari Bupati Buol dan juga dari Komisi Pemberantasan Korupsi (KPK) serta berbagai lembaga swadaya masyarakat sipil. Bupati Buol yang menjabat saat itu, yaitu Amiruddin Rauf, tidak sepakat dengan penerbitan SK MenLHK 517/2018 tersebut. Alasannya karena berdasarkan Rencana Tata Ruang Wilayah (RTRW) Kabupaten Buol, wilayah tersebut akan dijadikan sebagai kawasan cadangan pangan dan daerah resapan air untuk sumber irigasi. ${ }^{3}$

KPK menyatakan protes terhadap keputusan MenLHK untuk menerbitkan SK MenLHK 517/2018 tersebut karena menurut KPK izin yang dimaksud seharusnya tidak dapat diberikan karena diperoleh melalui tindak pidana korupsi

\footnotetext{
${ }^{2}$ Indonesia, Instruksi Presiden tentang Penundaan dan Evaluasi Perizinan Perkebunan Kelapa Sawit serta Peningkatan Produktivitas Perkebunan Sawit, No. 8 Tahun 2018, Diktum Kedua, ayat (1).

${ }^{3}$ Kompas, "Bupati Buol Geram KLHK Izinkan 9.964 Hektar Hutan Produksi Jadi Kebun Sawit". https:/ / regional.kompas.com/read/2019/01/22/17001771/bupati-buol-geram-klhk-izinkan-9964-hektar-hutan-produksi-jadi-kebun-sawit, diakses tanggal 5 September 2019.
} 
Dari Inpres Moratorium Sawit Hingga Kebijakan Tata Kelola Industri Sawit Presiden Jokowi: Studi Kasus Penerbitan SK Pelepasan Kawasan Hutan PT Hardaya Inti Plantations di Buol, Sulawesi Selatan

berupa suap. ${ }^{4}$ Sedangkan, salah satu lembaga masyarakat sipil, yaitu Greenomics Indonesia, menyatakan bahwa $80 \%$ dari areal pelepasan kawasan hutan untuk PT HIP tersebut masih berupa hutan lebat. Greenomics juga mengidentifikasi tutupan lahan berupa tanaman sawit yang terbentang di salah satu blok pada areal pelepasan kawasan hutan untuk PT HIP tersebut, yang mengindikasikan pelanggaran hukum. ${ }^{5}$

Meskipun mendapatkan protes keras dari berbagai pihak, di kesempatan yang berbeda, MenLHK menyatakan bahwa dari sisi legalitas, seluruh persyaratan, dokumen, dan dasar hukum penerbitan SK MenLHK 517/2018 tersebut sudah kuat, jadi tidak ada masalah dalam penerbitannya. ${ }^{6}$

Kasus PT HIP ini tentunya menarik untuk dianalisis lebih lanjut, terlebih bila dijadikan sebagai pintu masuk terhadap isu yang lebih besar, yaitu mengenai tata kelola industri sawit di Indonesia, terutama pada era Presiden Jokowi. Tulisan ini mencoba menelusuri lebih jauh fenomena tersebut dengan mengajukan dua rumusan masalah sebagai berikut:
1. Apakah Penerbitan SK MenLHK 517/2018 melanggar Inpres Moratorium Sawit?

2. Bagaimanakah arah kebijakan Presiden Jokowi terkait tata kelola industri sawit?

Dalam menjawab rumusan masalah yang telah diajukan, tulisan ini akan dibagi menjadi tiga bagian. Pertama, studi kasus penerbitan SK Pelepasan Kawasan Hutan PT HIP di Buol. Kedua, analisis terhadap kebijakan tata kelola industri sawit di era Presiden Jokowi. Ketiga, catatan kritis. Terakhir, tulisan ini akan ditutup dengan kesimpulan pada bagian penutup.

\section{Dugaan Pelanggaran Inpres Mo- ratorium Sawit dalam Studi Ka- sus PT HIP}

Berdasarkan Profil Perusahaan yang didapatkan dari Dirjen Administrasi Hukum Umum Kemenkumham, PT HIP adalah perseroan tertutup dengan nomor Surat Keputusan Pengesahan C2895.HT.01.01.TH.1996 yang bergerak di bidang perkebunan dan industri sawit. PT HIP juga merupakan anak perusahaan dari PT Central Cipta Murdaya atau

${ }^{4}$ Dian Maharani, “Hartati Murdaya Divonis 2 Tahun 8 Bulan Penjara” https://nasional.kompas. com/read/2013/02/04/12134267/Hartati.Murdaya.Divonis.2.Tahun.\%208.Bulan.Penjara, dan Viva, "KPK Geram Kementerian Kehutanan Masih Berikan Izin ke Hartati Murdaya" https://www.viva. co.id/berita/nasional/1115240-kpk-geram-kementerian-kehutanan-masih-berikan-izin-ke-hartatimurdaya, diakses tanggal 5 September 2019

${ }^{5}$ Greenomics Indonesia, "80\% areal pelepasan kawasan hutan PT HIP masih berhutan lebat", http://greenomics.org/80-areal-pelepasan-kawasan-hutan-pt-hip-masih-berhutan-lebat, diakses tanggal 5 September 2019.

${ }^{6}$ Nur Faizah Al Bahriyatul, “KLHK Sebut Administrasi Izin 9.964 ha Kebun Sawit di Buol Sudah Lengkap", https:/ /ekonomi.bisnis.com/read/20190121/99/880899/klhk-sebut-administrasi-izin-9.964- 
lebih dikenal dengan nama Group CCM. PT HIP juga telah mendapatkan sertifikasi ISPO dengan sertifikat BSI-ISPO $611530 .^{7}$

Pada tahun 2011 PT HIP mengajukan surat permohonan Izin Lokasi atas tanah seluas 4.500 hektare yang sudah telanjur ditanami kelapa sawit tersebut kepada Bupati Buol, Amran Batalipu, dengan mengatasnamakan PT Sebuku Inti Plantation (PT SIP) yang juga merupakan anak perusahaan PT CCM. Namun permohonan izin lokasi atas nama PT SIP hingga Tahun 2012 tidak keluar.

Pada tahun 2013, direktur PT HIP saat itu, Hartati Murdaya, ditangkap oleh KPK saat melakukan suap kepada Bupati Buol Amran Batalipu. Suap tersebut terkait kepengurusan Izin Usaha Perkebunan (IUP) dan Hak Guna Usaha (HGU) untuk PT HIP di Buol, Sulawesi Tengah. Keduanya telah divonis oleh pengadilan dengan hukuman bagi Amran selama 7 tahun penjara dan denda Rp300 juta, sedangkan Hartati dihukum 2 tahun 8 bulan penjara dan denda Rp150 juta. ${ }^{8}$

Lima tahun kemudian, Menteri LHK menerbitkan SK MenLHK 517/2018 yang memberikan izin pelepasan kawa- san hutan untuk perkebunan sawit PT HIP. Berdasarkan SK tersebut, diketahui kronologi permohonan perizinan yang diajukan oleh PT HIP sebagai berikut:

1. Persetujuan pencadangan kawasan hutan seluas 31.750 hektare sudah ada sejak tanggal 27 Februari 1997 berdasarkan Surat Keputusan Menteri Kehutanan No. 238/Menhut-II/1997 yang diberikan kepada PT Cipta Cakra Murdaya (PT CCM). PT HIP sendiri merupakan anak usaha dari PT CCM dan sudah mendapatkan pelimpahan izin-izin lokasi untuk keperluan perkebunan dari PT CCM.

2. PT HIP sudah mengajukan permohonan tata batas ulang sejak tanggal 4 Juni 2014.

3. Areal yang dapat ditindaklanjuti dengan penataan batas ulang seluas 10.028 hektare, dari sebelumnya HPK yang dimohonkan seluas 16.065 hektare tetapi terdapat areal hutan primer seluas 6.037 hektare sehingga areal tersebut harus dikecualikan dari penataan batas. Informasi ini berdasarkan Surat Direktur Jenderal Planologi Kehutanan dan Tata Lingkungan Kementerian Lingkungan Hidup dan Kehutanan Nomor S.794/

\footnotetext{
ha-kebun-sawit-di-buol-sudah-lengkap, diakses tanggal 5 September 2019.

${ }^{7}$ Indonesia, Kementerian Hukum dan Hak Asasi Manusia, SK Pengesahan No. C2-895.HT.01.01. TH.1996 a.n. PT Hardaya Inti Plantations.

${ }^{8}$ Indonesia, Putusan PN Jakarta Pusat No.64/Pid.B/TPK/2012/PN.Jkt.Pst dan Putusan PT DKI Jakarta No. 12/PID/TKP/2013/PT.DKI. Keduanya telah berkekuatan hukum tetap karena Amran mencabut permohonan kasasinya melalui Penetapan No. 1552 K/Pid.Sus/2013.
} 
Dari Inpres Moratorium Sawit Hingga Kebijakan Tata Kelola Industri Sawit Presiden Jokowi: Studi Kasus Penerbitan SK Pelepasan Kawasan Hutan PT Hardaya Inti Plantations di Buol, Sulawesi Selatan

MenLHK-PKTL/2015 tanggal 15 Desember 2015.

4. Bahwa realisasi lahan setelah tata batas adalah seluas 9.964 hektare dan disetujui pada tanggal 19 Oktober 2017 melalui Surat No. S. 1433 / P K T L / K U H / PLA.2/10/2017.

5. SK MenLHK 517/2018 tersebut ditetapkan pada tanggal 23 November 2018.

6. Inpres Moratorium Sawit diterbitkan pada tanggal 19 September 2018. Dengan demikian dapat dipastikan bahwa SK MenLHK 517/2018 terbit berselang dua bulan setelah Inpres Moratorium Sawit diberlakukan.

Salah satu kritik masyarakat sipil terhadap SK MenLHK 517/2018 adalah bahwa Surat Keputusan tersebut sama sekali tidak memuat informasi apakah kawasan hutan yang dilepas merupakan kawasan hutan produksi yang dapat dikonversi (HPK) yang produktif atau nomproduktif. ${ }^{9}$ Fakta ini penting karena hanya kawasan hutan nonproduktif saja yang dapat dilepaskan. ${ }^{10}$

Selain itu, juga terdapat rilis dari Walhi Sulawesi Tengah yang didasarkan pada data dari Ombudsman Republik Indonesia Perwakilan Sulawesi Tengah dan KPK pada tanggal 1 April 2019, yang menyatakan bahwa PT HIP patut diduga memperoleh Izin Lokasi dengan cara-cara yang tidak sah dan melanggar peraturan, karena dalam ketentuan perseroan terbatas izin-izin tidak bisa dialihkan tanpa persetujuan pemberi izin. ${ }^{11}$ Hal ini telah dipertegas dalam Keputusan Kepala Kantor Pertanahan Kabupaten Buol Toli-Toli Nomor 400-517 tanggal 17 November 1999, bagian pertama, angka 5 yang menyatakan "Pemberian izin lokasi ini hanya diperuntukkan bagi usaha perkebunan kelapa sawit serta pembangunan fasilitas prasarana dan sarananya oleh penerima izin lokasi dan tidak dibenarkan bagi peruntukan lain dan oleh pihak lain selain penerima izin lokasi". ${ }^{12}$

Apabila dicermati dengan seksama, ketentuan yang termuat dalam Inpres Moratorium Sawit maupun Peraturan Menteri Lingkungan Hidup dan Kehutanan No. P.96/MENLHK/SETJEN/ KUM.1/11/2018 (Permen LHK No 96/2018) tentang Tata Cara Pelepasan Kawasan Hutan Produksi yang Dapat Dikonversi memang memiliki pengecua-

\footnotetext{
${ }^{9}$ Sawit Watch, et al. "Shadow Report: Kemana Arah Implementasi Inpres No. 8 Tahun 2018 Berjalan?" disampaikan dalam Diskusi Publik Moratorium Sawit di Jakarta, 17 Mei 2019, hlm. 44.

${ }^{10}$ Indonesia, Menteri Lingkungan Hidup dan Kehutanan, Peraturan tentang Tata Cara Pelepasan Kawasan Hutan Produksi yang Dapat Dikonversi, No. 96 Tahun 2018 Pasal 41 ayat (6).

${ }^{11}$ Indonesia, Undang-Undang tentang Perkebunan, No. 39 Tahun 2014 LN No. 308, TLN No. 5613, Pasal 15.

${ }^{12}$ Indonesia, Ombudsman Sulawesi Tengah, “Ombudsman Temukan Maladministrasi Perkebunan Sawit di Sulteng" https://ombudsman.go.id/perwakilan/news/r/pwk--ombudsman-temukan-
} 
lian diperbolehkannya penerbitan Surat Keputusan Pelepasan Kawasan Hutan pasca berlakunya Inpres Moratorium Sawit, yaitu:

1. Apabila permohonan pelepasan kawasan hutan telah mendapat persetujuan prinsip sebelum berlakunya Inpres Moratorium Sawit, namun belum ditatabatas dan berada di kawasan HPK yang masih produktif dan tidak produktif, maka permohonan dapat diproses hanya pada kawasan HPK yang tidak produktif; ${ }^{13}$

2. Apabila permohonan pelepasan kawasan hutan telah mendapat persetujuan prinsip dan sudah ditata batas sebelum berlakunya Inpres Moratorium Sawit, maka permohonan dapat diproses sepanjang kawasan HPK yang dimohonkan tidak produktif,;

3. Penundaan berdasarkan Inpres Moratorium Sawit hanya untuk perkebunan kelapa sawit yang (1) mengajukan permohonan baru, (2) permohonan yang telah diajukan namun belum melengkapi persyaratan, atau telah me- menuhi persyaratan namun berada pada kawasan hutan yang masih produktif, atau (3) permohonan yang telah mendapat persetujuan prinsip namun belum ditata batas dan berada di kawasan hutan yang masih produktif; 15

4. Bahwa penundaan berdasarkan Inpres Moratorium Sawit dikecualikan untuk permohonan pelepasan atau tukar menukar kawasan hutan untuk perkebunan kelapa sawit yang telah ditanami dan diproses berdasarkan ketentuan Pasal 51 Peraturan Pemerintah No. 104 Tahun 2015 (PP 104/2015); ${ }^{16}$

5. Kawasan Hutan Produksi yang dapat dilakukan pelepasan berupa Kawasan Hutan Produksi yang dapat Dikonversi yang Tidak Produktif, kecuali pada provinsi yang tidak tersedia lagi kawasan Hutan Produksi yang Dapat Dikonversi yang Tidak Produktif; ${ }^{17}$

6. Yang dimaksud dengan "Hutan Produksi yang Dapat Dikonversi yang Tidak Produktif" berupa

maladministrasi-perkebunan-sawit-di-sulteng, dan https://komiu.id/wp-content/uploads/2019/03/ SULAWESI-TENGAH-BRIEF-OK.pdf, diunduh tanggal 17 Desember 2019.

${ }^{13}$ Indonesia, Peraturan Menteri Lingkungan Hidup dan Kehutanan, PermenLH tentang Tata Cara Pelepasan Kawasan Hutan Produksi yang Dapat Dikonversi, No. 96 Tahun 2018 Pasal 41 ayat (5).

${ }^{14} \mathrm{Ibid}$. , ayat (6).

${ }^{15}$ Indonesia, Inpres tentang Penundaan dan Evaluasi Perizinan Perkebunan Kelapa Sawit serta Peningkatan Produktivitas Perkebunan Kelapa Sawit, Diktum Kedua, No. 8 Tahun 2018 Nomor 1.

${ }^{16} \mathrm{Ibid}$., Nomor 2.

${ }^{17}$ Indonesia, Peraturan Pemerintah tentang Tata Cara Perubahan Peruntukan dan Fungsi Kawasan Hutan, No. 104 Tahun 2015, LN No. 326, TLN No. 5794, Pasal 19 ayat (1). 
Dari Inpres Moratorium Sawit Hingga Kebijakan Tata Kelola Industri Sawit Presiden Jokowi: Studi Kasus Penerbitan SK Pelepasan Kawasan Hutan PT Hardaya Inti Plantations di Buol, Sulawesi Selatan

Hutan Produksi yang penutupan lahannya didominasi lahan tidak berhutan antara lain semak belukar, lahan kosong, dan kebun campur;:18

7. Pelepasan Kawasan Hutan untuk kepentingan pembangunan di luar kegiatan kehutanan hanya dapat dilakukan pada kawasan HPK yang memenuhi kriteria: ${ }^{19}$

a. Fungsi HPK sesuai dengan ketentuan peraturan perundang-undangan;

b. Tidak dibebani izin penggunaan Kawasan Hutan, Izin Pemanfaatan Hutan dan/atau perizinan lainnya dari Menteri, serta tidak berada pada Kawasan Hutan yang ditetapkan sebagai Kawasan Hutan dengan Tujuan Khusus (KHD$\mathrm{TK})$;

c. Tidak produktif, kecuali pada provinsi yang sudah tidak tersedia lagi kawasan HPK yang tidak produktif; dan

d. Berada pada provinsi yang luas kawasan hutannya di atas $30 \%$.

Berdasarkan fakta-fakta tersebut, apabila disandingkan dengan substansi
SK MenLHK 517/2018, sama sekali tidak ada informasi yang secara tegas menyatakan bahwa kawasan hutan yang dilepas dalam SK 517/2018 merupakan kawasan HPK yang tidak produktif sesuai dengan ketentuan yang mengaturnya.

Terkait kondisi nyata di lapangan, terdapat investigasi dan analisis kawasan hutan dari koalisi masyarakat sipil yang termuat dalam shadow report Inpres Moratorium Sawit. Analisis spasial tersebut menyatakan bahwa kawasan hutan yang dilepas ternyata sudah ditanami sawit. ${ }^{20}$ Investigasi dari Ombudsman Republik Indonesia Perwakilan Sulawesi Tengah yang turut dimuat dalam laporan tersebut pun menghasilkan temuan yang serupa, di mana pengambilan foto dari pesawat nirawak pada 27 April 2018 memperlihatkan adanya barisan tanaman sawit di dalam kawasan yang dilepaskan melalui SK MenLHK 517/2018. ${ }^{21}$

Temuan Ombudsman tersebut menimbulkan dua konsekuensi berbeda. Pertama, kawasan yang dilepas melalui SK MenLHK 517/2018 masih berupa hutan produktif yang menurut peraturan tidak boleh dilepaskan menjadi Areal Penggunaan Lain (APL). Kedua, penanaman sawit sudah dilakukan di kawa-

\footnotetext{
${ }_{18}$ Ibid., Penjelasan Pasal 19 ayat (1). Lihat juga Indonesia, Peraturan Menteri Lingkungan Hidup dan Kehutanan No. 96 Tahun 2018 tentang Tata Cara Pelepasan Kawasan Hutan Produksi yang Dapat Dikonversi, Pasal 1 angka 5.

${ }^{19}$ Indonesia, Peraturan Menteri Lingkungan Hidup dan Kehutanan tentang Tata Cara Pelepasan Kawasan Hutan Produksi yang Dapat Dikonversi, No. 96 Tahun 2018 Pasal 2 ayat (1) dan (2).

${ }^{20}$ Sawit Watch, Op. Cit., hlm. 32.

${ }^{21}$ Ibid., hlm. 33.
} 
san hutan sebelum kawasan hutan tersebut dilepaskan. Fakta kedua tersebut justru menunjukkan sudah terjadinya pelanggaran hukum, yaitu penanaman sawit di kawasan hutan sebelum adanya pelepasan kawasan hutan, yang bahkan memiliki sanksi pidana karena melanggar ketentuan dalam Undang-Undang No. 18 Tahun 2013 tentang Pencegahan dan Pemberantasan Perusakan Hutan (UU P3H). ${ }^{22}$

Tanpa adanya penjelasan lebih lanjut mengenai hasil temuan dan investigasi kondisi nyata kawasan hutan versi masyarakat sipil oleh Kementerian Lingkungan Hidup dan Kehutanan dan sampai dapat dibuktikan sebaliknya, SK MenLHK 517/2018 dapat dinyatakan bertentangan dengan ketentuan PP 104/2015, Permen LHK 96/2018, dan Inpres Moratorium Sawit, sehingga dapat dikategorikan sebagai suatu bentuk cacat substantif dalam penerbitan keputusan.

Apabila dugaan cacat substansi dalam bentuk pelepasan kawasan hutan yang masih produktif tersebut terbukti, maka Men LHK dibenarkan oleh peraturan perundang-undangan untuk mencabut dan memperbaiki SK MenLHK 517/2018 tanpa perlu menunggu sengke- ta tata usaha negara diputus oleh pengadilan. Pencabutan tersebut juga selaras dengan pelaksanaan asas self-correction ${ }^{23}$ dan Asas-Asas Umum Pemerintahan yang Baik (AUPB) sebagaimana telah diamanatkan juga dalam Undang-Undang No. 30 Tahun 2014 tentang Administrasi Pemerintahan. ${ }^{24}$

Berdasarkan pemaparan tersebut, maka jawaban terhadap rumusan masalah pertama adalah SK MenLHK 517/2018 tentang Pelepasan Kawasan Hutan PT HIP patut diduga keras telah melanggar Inpres Moratorium Sawit dan UU P3H. Karena ketiadaan informasi yang termuat dalam SK MenLHK 517/2018, maka perlu adanya klarifikasi atau bahkan investigasi lebih lanjut dari Kementerian Lingkungan Hidup dan Kehutanan bahwa memang kawasan hutan yang dilepaskan tersebut bukanlah hutan produktif yang dilarang untuk dilepaskan berdasarkan peraturan perundang-undangan, serta menindaklanjuti temuan Ombudsman bahwa sudah ada penanaman sawit di kawasan hutan sebelum adanya pelepasan kawasan hutan. Sayangnya, hingga tulisan ini dibuat, belum ada klarifikasi lebih lanjut dari Kementerian Lingkungan Hidup dan

\footnotetext{
${ }^{22}$ Indonesia, Undang-Undang tentang Pencegahan dan Pemberantasan Perusakan Hutan, No. 18 Tahun 2013, LN No. 130, TLN No. 5432, Pasal 92.

${ }^{23}$ Suatu bentuk pendekatan positif di mana pejabat pemerintah melakukan otokoreksi atau perbaikan atas penerbitan suatu keputusan tata usaha negara. Lebih lanjut lihat Junaedi, "Formele Wederrechtelijkheid dan Self-Correction dalam Penyelenggaraan Administrasi Pemerintahan", tanpa tahun, hlm. 7.

${ }^{24}$ Indonesia, Undang-Undang tentang Administrasi Pemerintahan, No. 30 Tahun 2014 LN No. 292, TLN No. 5601, Pasal 66 ayat (4), (5) dan (6).
} 
Dari Inpres Moratorium Sawit Hingga Kebijakan Tata Kelola Industri Sawit Presiden Jokowi: Studi Kasus Penerbitan SK Pelepasan Kawasan Hutan PT Hardaya Inti Plantations di Buol, Sulawesi Selatan

Kehutanan mengenai temuan dan investigasi masyarakat sipil terhadap kawasan hutan yang dilepaskan.

\section{Kebijakan Tata Kelola Industri Sawit Presiden Jokowi}

Kasus penanaman sawit sebelum adanya Surat Keputusan pelepasan kawasan hutan hingga pemberian Surat Keputusan yang patut diduga keras melanggar peraturan perundang-undangan untuk perkebunan sawit PT HIP tentunya menarik untuk ditelusuri lebih lanjut dalam lingkup yang lebih luas. Seringkali kasus-kasus seperti ini dianggap sebagai suatu bentuk "keterlanjuran" hingga akhirnya diberikan suatu legalitas atau dikenal dengan "pemutihan." Kasus tersebut dapat menjadi pintu masuk untuk melangkah dan melihat lebih jauh bagaimana sebenarnya Indonesia, khususnya dalam pemerintahan Presiden Jokowi, menyusun kebijakan dan peraturan mengenai industri sawit. Dalam perkembangannya, selain Inpres Moratorium Sawit yang telah dipaparkan di atas, se- tidaknya terdapat empat kebijakan lainnya yang terkait erat dengan tata kelola industri ini, termasuk dengan studi kasus PT HIP yang diangkat, yaitu Indonesia Sustainable Palm Oil (ISPO), Rancangan Undang-Undang Perkelapasawitan, Peraturan Pemerintah No. 24 tahun 2018 tentang Pelayanan Perizinan Berusaha Terintegrasi Secara Elektronik (PP OSS), dan Omnibus Law.

\section{A. Indonesian Sustainable Palm Oil (ISPO)}

ISPO adalah suatu bentuk sertifikasi yang menyatakan bahwa sawit yang dikelola dan dihasilkan dari suatu pelaku usaha adalah sawit yang berkelanjutan dengan turut mempertimbangkan faktor Hak Asasi Manusia, sosial, dan lingkungan. ${ }^{25}$ Pengaturan mengenai ISPO sudah ada sejak tahun 2011 yang kemudian turut diubah di tahun 2015 karena menyesuaikan dengan Undang-Undang Perkebunan yang baru. ${ }^{26}$ Indonesia sendiri hanya mewajibkan sertifikasi ISPO kepada perusahaan perkebunan, se-

\footnotetext{
${ }^{25} \mathrm{Hal}$ ini tercermin dari syarat untuk mendapatkan sertifikat ISPO, di mana perusahaan harus memenuhi 7 prinsip, yakni (1) legalitas usaha perkebunan, (2) manajemen perkebunan, (3) perlindungan terhadap pemanfaatan hutan alam primer dan lahan gambut, (4) pengelolaan dan pemantauan lingkungan, (5) tanggung jawab terhadap pekerja, (6) tanggung jawab sosial dan pemberdayaan ekonomi masyarakat, dan (7) peningkatan usaha secara berkelanjutan. Lihat Permentan No. 11 Tahun 2015 tentang Sistem Sertifikasi Kelapa Sawit Berkelanjutan Indonesia (Indonesian Sustainable Palm Oil Certification System), Lampiran II.

${ }^{26}$ Indonesia, Menteri Pertanian. Peraturan Menteri Pertanian No. 19 Tahun 2011 yang telah dicabut dengan Indonesia, Peraturan Menteri Pertanian tentang Sistem Sertifikasi Kelapa Sawit Berkelanjutan Indonesia (Indonesian Sustainable Palm Oil Certification System) No. 11 Tahun 2015. Lihat juga Indonesia, UndangUndang tentang Perkebunan, No. 39 Tahun 2014 LN No. 308, TLN No. 5613.
} 
dangkan bagi pekebun sawit swadaya atau skala kecil tidak diwajibkan. ${ }^{27}$

Menurut Indrapraja, posisi ISPO dalam instrumen penaatan hukum lingkungan adalah suatu bentuk penaatan wajib. ${ }^{28}$ Kesimpulan tersebut diambil setelah Indrapraja membandingkan ISPO dengan instrumen serupa yang diberlakukan di negara lain, yaitu RSPO (Roundtable Sustainable Palm Oil Certification) yang berlaku secara global namun bersifat sukarela dan MSPO (Malaysian Sustainbale Palm Oil Certification) yang berlaku di Malaysia. ${ }^{29}$

Dengan adanya ISPO, idealnya posisi dan komitmen Indonesia sebagai produsen sawit yang berkelanjutan menjadi lebih kuat. Namun, tidak semua perusahaan sawit yang bersertifikasi ISPO otomatis menjadi produsen yang bertanggung jawab dari sisi hukum, sosial, hingga lingkungan. PT HIP sendiri telah memiliki sertifikat ISPO dengan nomor BSI-ISPO 612530. Namun, rentetan kasus yang menerpa PT HIP dari korupsi hing- ga pelepasan kawasan hutan tentunya menjadi catatan kritis tersendiri, apakah memang ISPO masih dapat digunakan sebagai suatu standar keberlanjutan atau penaatan yang kuat?

\section{B. Rancangan Undang-Undang Perkelapasawitan}

Indonesia menganggap sawit sebagai industri yang sangat strategis. Badan Pusat Statistik mencatat bahwa sejak tahun 2016, Indonesia telah menjadi pengekspor terbesar minyak sawit mentah, mengalahkan Malaysia. ${ }^{30}$ Bahkan kontribusi industri sawit terhadap Produk Domestik Bruto (PDB) Indonesia jauh mengalahkan industri minyak dan gas bumi. ${ }^{31}$ Bappenas pun turut menyatakan bahwa industri sawit turut berkontribusi menyediakan lapangan pekerjaan bagi 16,2 juta orang di Indonesia, setara dengan $10 \%$ seluruh populasi produktif di Indonesia. ${ }^{32}$ Karena sifatnya yang sangat strategis tersebut, pada tahun 2016, Rancangan Undang-Undang Perkelapasawitan diusulkan oleh Dewan Perwakilan

\footnotetext{
${ }^{27}$ Indonesia, Menteri Pertanian. Peraturan Menteri Pertanian tentang Sistem Sertifikasi Kelapa Sawit Berkelanjutan Indonesia (Indonesian Sustainable Palm Oil Certification System), No. 11 Tahun 2015, Pasal 2 ayat (2) dan (3).

${ }^{28}$ Fadhil Muhammad Indrapraja, "Sertifikasi Minyak Kelapa Sawit Berkelanjutan Sebagai Instrumen Penaatan Hukum Lingkungan: Analisis Hukum Terhadap Indonesian Sustainable Palm Oil, Roundtable on Sustainable Palm Oil, dan Malaysian Sustainable Palm Oil", Skripsi Fakultas Hukum Universitas Indonesia, 2017, hlm. 114.

${ }^{29} \mathrm{Ibid} ., \mathrm{hlm}$. 115. Sebagai catatan tambahan, Malaysia telah mengumumkan bahwa MSPO diberlakukan secara wajib bagi seluruh pelaku industri kelapa sawit di Malaysia mulai akhir tahun 2019.

${ }^{30}$ Badan Pusat Statistik, Statistik Kelapa Sawit Indonesia, (Jakarta: BPS, 2017), hlm. 11.

${ }^{31} \mathrm{Ibid} .$, hlm. xvii.

${ }^{32}$ Francisca Christy Rosana, "Said Didu: Pertamina Dilarang Impor Migas, Rakyat Mati", https:// bisnis.tempo.co/read/1142496/bappenas-industri-kelapa-sawit-serap-162-juta-tenaga-kerja, diakses 8 November 2019.
} 
Dari Inpres Moratorium Sawit Hingga Kebijakan Tata Kelola Industri Sawit Presiden Jokowi: Studi Kasus Penerbitan SK Pelepasan Kawasan Hutan PT Hardaya Inti Plantations di Buol, Sulawesi Selatan

Rakyat untuk turut masuk pada Program Legislasi Nasional (Prolegnas).

Rancangan Undang-Undang Perkelapasawitan dinilai kontroversial oleh kalangan masyarakat sipil dan akademisi. Sebagian besar materi muatan Rancangan Undang-Undang Perkelapasawitan hanya memuat ulang ketentuan yang sudah ada di Undang-Undang Perkebunan dengan membuatnya lebih spesifik untuk sawit dengan ketentuan sanksi yang lebih ringan. ${ }^{33}$ Sedangkan dari sisi akademisi, Pradiptyo dan Tjandar, menyatakan beberapa catatan kritis terhadap Rancangan Undang-Undang tersebut, antara lain (1) naskah akademik mencakup permasalahan krusial di sektor perkelapasawitan, (2) sebagian besar aturan masih serupa dengan Undang-Undnag Perkebunan, (3) membebankan risiko bisnis korporasi kepada sektor publik, dan (4) sanksi yang lebih ringan dan tidak mengatur kejahatan korporasi. ${ }^{34}$ Adanya Rancangan UndangUndang Perkelapasawitan setidaknya telah menunjukkan betapa industri sawit ini sangat "penting" sehingga harus diatur oleh Undang-Undang tersendiri.

\section{PP OSS}

Presiden Jokowi juga sangat mendorong adanya kemudahan mendapatkan perizinan yang ditandai dengan penerbitan PP OSS. Dengan adanya PP OSS, praktis seluruh perizinan dan sektor yang diatur dalam PP OSS dapat diurus secara online dan dengan jangka waktu lebih singkat. Perkebunan kelapa sawit termasuk dalam sektor yang perizinannya sekarang diatur oleh PP OSS. ${ }^{35} \mathrm{Ke}-$ menterian Pertanian pun sudah menerbitkan peraturan teknis turunan dari PP OSS tersebut untuk proses perizinannya melalui Peraturan Menteri Pertanian No. 5 Tahun 2019.

Sebelum adanya PP OSS, perusahaan perkebunan harus memenuhi syaratsyarat berikut secara berurutan sebelum dapat melakukan kegiatan usaha: 1) mendapatkan Izin Lokasi, 2) mengurus AMDAL, Surat Keputusan Kelayakan Lingkungan Hidup (SKKLH), dan Izin Lingkungan, 3) mendapatkan IUP, 4) mengurus Izin Pelepasan Kawasan Hutan (IPKH) apabila IUP berada pada kawasan Hutan Produksi yang Dapat Dikonversi (HPK), atau Izin Tukar-Menukar Kawasan (ITMK) apabila IUP berada

${ }^{33}$ ICEL, “Lembar Fakta Perancangan RUU Perkelapasawitan: Kajian tentang Kebutuhan Pengaturan", 31 Mei 2018, hlm. 3-8.

${ }^{34}$ Rimawan Pradiptyo dan Riawan Tjandra, "Pembebanan Risiko Bisnis Korporasi kepada Sektor Publik: Kajian Terhadap RUU Perkelapasawitan”, hlm. 53-54, https:/ / www.tuk.or.id/wp-content/uploads/2018/02/Kajian-terhadap-RUU-Kepala-Sawit-1.pdf, diakses tanggal 8 November 2019.

${ }^{35}$ Indonesia, Peraturan Pemerintah tentang Pelayanan Perizinan Berusaha Terintegrasi Secara Elektronik (Online Single Submission), PP No. 24 Tahun 2018, LN No. 90, TLN No. 6215, Pasal 85 huruf b dan c. 
di kawasan Hutan Produksi Terbatas (HPT) atau Hutan Produksi Tetap (HP), 5) memiliki HGU. ${ }^{36}$

Sedangkan pasca PP OSS, IUP dapat diterbitkan terlebih dahulu berdasarkan komitmen, di mana pelaku usaha dapat segera melakukan kegiatan penunjang usaha, yaitu kegiatan selain kegiatan utama yang dimohonkan dalam izin. ${ }^{37}$ Pelaku usaha kemudian memenuhi semua komitmen diantaranya: Izin Lokasi, Izin Lingkungan, IPKH, dan HGU, dalam jangka waktu 2 bulan. ${ }^{38}$ Proses penerbitan ini jauh lebih cepat dibandingkan proses perizinan sebelumnya yang dapat memakan waktu bertahun-tahun karena harus mengurus AMDAL.

\section{Omnibus Law}

Dengan segala kemudahan dan akselerasi perizinan tersebut, Presiden Jokowi masih merasa proses tersebut lama dibandingkan dengan negara lain seperti Vietnam. ${ }^{39}$ Hingga akhirnya muncullah wacana omnibus law yang disampaikan dalam pidato pelantikannya pada $20 \mathrm{Ok}$ tober 2019 yang lalu. ${ }^{40}$ Tujuan dari omnibus law ini sendiri adalah mempermudah seluruh perizinan terkait investasi, agar investor asing tertarik menanamkan modalnya di Indonesia dan akhirnya memacu pertumbuhan ekonomi.

Black's Law Dictionary mendefinisikan omnibus law sebagai "a single bill containing various distinct matters, usually drafted in this way to force the executive either to accept all the unrelated minor provisions or to veto the major provisions" ${ }^{41} \mathrm{Me}-$ nurut Krutz, omnibus law adalah praktik penggabungan beberapa ketentuan dari berbagai peraturan perundang-undangan ke dalam satu Undang-Undang saja. Praktik ini dikenal di negara-negara penganut common law seperti Amerika Serikat. ${ }^{42}$ Dalam kesimpulan penelitiannya, Krutz menyatakan bahwa omnibus law menimbulkan dampak positif terhadap produktivitas legislatif karena dapat

\footnotetext{
${ }^{36}$ Disarikan dari Indonesia, Peraturan Menteri Pertanian tentang Pedoman Perizinan Usaha Perkebunan, PerMen Pertanian No. 98 Tahun 2013 dan Putusan MK No. 138/PUU-XIII/2015.

${ }^{37}$ Sebagai contoh, setelah mengantongi IUP berdasarkan komitmen, pelaku usaha sudah dapat melakukan kegiatan pembebasan tanah untuk perkebunan, tetapi belum dapat melakukan penanaman.

${ }^{38}$ Indonesia, Menteri Pertanian. Permen Pertanian tentang Tata Cara Perizinan Berusaha Sektor Pertanian, Permen Pertanian No. 5 Tahun 2019 Pasal 8 dan Pasal 13 ayat (1).

${ }^{39}$ Chandra Gian Asmara, “Jokowi Kesal: Izin Investasi di Vietnam 2 Bulan, RI Tahunan”, https:// www.cnbcindonesia.com/news/20190904181346-4-97155/jokowi-kesal-izin-investasi-di-vietnam2-bulan-ri-tahunan, diakses tanggal 8 November 2019.

${ }^{40}$ Luthfia Ayu Anazella, "Apa Itu Omnibus Law, yang Disinggung Jokowi dalam Pidatonya?”, , https://www.kompas.com/tren/read/2019/10/22/070600665/apa-itu-omnibus-law-yang-disinggungjokowi-dalam-pidatonya-?page=all, diakses tanggal 8 November 2019.

${ }^{41}$ Bryan A. Garner, Black's Law Dictionary 9th ed. (Minnesota: West Publishing Co, 2009), hlm. 186.

${ }^{42}$ Glen S. Krutz, "Getting Around Gridlock: The Effect of Omnibus Utilization on Legislative Productivity", Legislative Studies Quarterly, Vol. 25, No. 4 (November 2000), hlm. 533.
} 
Dari Inpres Moratorium Sawit Hingga Kebijakan Tata Kelola Industri Sawit Presiden Jokowi: Studi Kasus Penerbitan SK Pelepasan Kawasan Hutan PT Hardaya Inti Plantations di Buol, Sulawesi Selatan

memangkas birokrasi perizinan..$^{43}$ Berdasarkan pendapat Krutz ini, menjadi jelas bahwa langkah yang hendak diambil Presiden Jokowi adalah suatu bentuk penyederhanaan perizinan untuk mempermudah investasi masuk ke Indonesia.

Sebagai penutup dari subbab ini dan untuk menjawab rumusan masalah kedua, arah kebijakan Presiden Jokowi terkait tata kelola industri sawit, dalam pandangan Penulis, cenderung condong pada kepentingan ekonomi dan investasi. Hal ini terlihat dari berbagai kebijakan dengan narasi yang serupa, yaitu untuk pertumbuhan ekonomi dan mendapatkan lebih banyak investasi dari luar untuk pembangunan Indonesia. Namun, patut disayangkan bahwa tujuan tersebut membuat sektor lain seperti perlindungan lingkungan hidup menjadi "dikorbankan" untuk ekonomi dan investasi semata.

\section{Catatan Kritis atas Tata Kelola Industri Sawit}

Berdasarkan pemaparan di atas mengenai studi kasus PT HIP di Buol, yang mengarah kepada terjadinya keterlanjuran hingga penyelundupan hukum, serta arah kebijakan industri sawit, tentunya terdapat beberapa catatan kritis yang dapat disampaikan. Setidaknya terdapat tiga catatan kritis atas fenomena tersebut.
Pertama, Inpres Moratorium Sawit masih belum dapat diandalkan sepenuhnya. Adanya kasus seperti PT HIP tentunya menimbulkan pertanyaan akan keseriusan pemerintah dalam melaksanakan Inpres. Apabila di kemudian hari muncul kasus-kasus seperti PT HIP yang seolah-olah mengakali Inpres Moratorium Sawit demi menutupi pelanggaran hukum yang telah terjadi, tentunya akan menjadi rapor merah dalam hal penegakan hukum lingkungan.

Kedua, arah kebijakan yang dipilih Presiden Jokowi dalam tataran teoretis senada dengan pendekatan race to the bottom atau Delaware Effect. Kebijakan seperti PP OSS dan omnibus law dapat dikategorikan sebagai kebijakan yang mendukung pendekatan ini. Menurut Vig dan Kraft, istilah delaware effect tersebut digunakan untuk menggambarkan kebijakan negara atau suatu daerah yang cenderung melonggarkan peraturan-peraturan terkait dengan ekono$\mathrm{mi}$, bisnis, hingga pemberian insentif seperti pengurangan pajak bagi masuknya investasi. Sebagai contoh, Gubernur Wisconsin yang mengurangi staff Dinas Lingkungan Hidup daerahnya dengan tujuan mempercepat persetujuan penerimaan Izin Lingkungan. ${ }^{44}$

Dalam penelitiannya, Subramanian menyatakan bahwa Delaware Effect me-

${ }^{43} \mathrm{Ibid} ., \mathrm{hlm} .545$.

${ }^{44}$ Norman J. Vig dan Michael E. Kraft, Environmental Policy: New Directions for the Twenty-First Century, (London: SAGE Publications, 2019), hlm. 94. 
mang terbukti meningkatkan investasi dan keuntungan perusahaan karena terciptanya ekosistem bisnis yang memadai. Namun, efek yang ditimbulkannya terbatas atau hanya bersifat sementara. ${ }^{45}$ Sedangkan Raworth menyatakan bahwa tanpa adanya indikator yang jelas mengenai keseimbangan antara fondasi sosial-ekonomi dan perlindungan lingkungan, maka pertumbuhan ekonomi hanya akan menimbulkan kerugian yang jauh lebih besar dalam jangka panjang. ${ }^{46}$

Ketiga, paradigma yang dibangun dalam kebijakan industri sawit Presiden Jokowi yang hanya mementingkan ekonomi dan investasi juga serupa dengan logika environmental kuznet curve (EKC) atau lazim disebut Kurva Kuznet. Awalnya kurva tersebut dibuat untuk menggambarkan kesenjangan (inequality) yang meningkat seiring dengan pertumbuhan ekonomi suatu negara. Namun, lamakelamaan akan berangsur-angsur turun menemukan keseimbangannya. ${ }^{47}$ Seiring waktu, pertumbuhan ekonomi yang ditunjukkan kurva tersebut ternyata juga dianggap berkorelasi dengan perbaikan kondisi lingkungan yang terjadi. Mem- baiknya kondisi ekonomi yang ditunjukkan dengan pertumbuhan ekonomi, konon akan turut memperbaiki pencemaran lingkungan yang ditimbulkannya. ${ }^{48}$

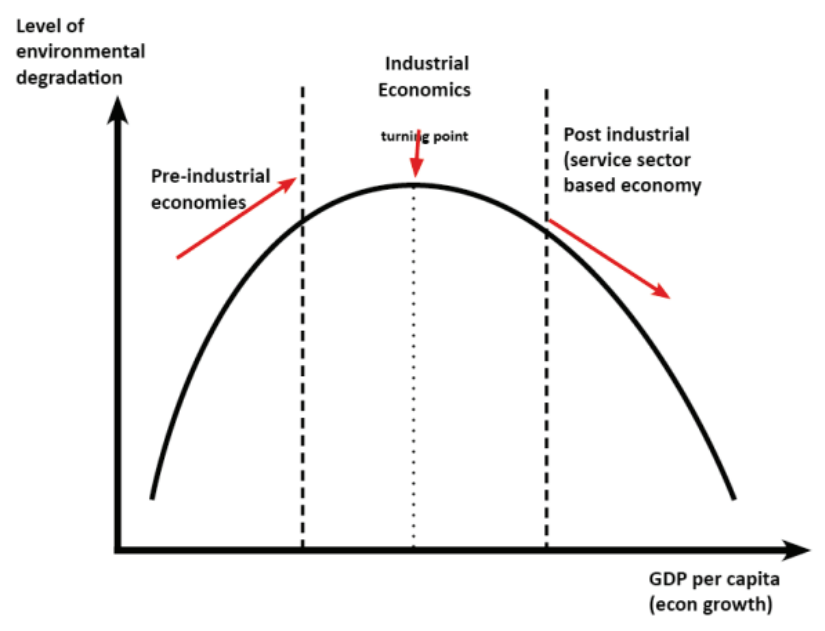

\section{Gambar 1. Environmental Kuznet Kurve. Sumber: Economics Help. ${ }^{49}$}

Meskipun demikian, banyak ahli tidak percaya bahwa ada bukti memadai yang menyatakan hubungan langsung antara pertumbuhan ekonomi dan meningkatnya kualitas lingkungan. Abdulai dan Ramcke juga menyatakan bahwa EKC belum tentu dapat digeneralisasi berlaku sama di seluruh negara karena faktor-faktor yang mempengaruhinya berbeda, seperti pendapatan per-kapita

\footnotetext{
${ }^{45}$ Guhan Subramanian, “The Disappearing Delaware Effect”, Journal of Law, Economics, E Organization, Vol. 20, No. 1, April 2004, hlm. 57.

${ }^{46}$ Kate Raworth, Doughnut Economics: Seven Ways to Think Like a 21 ${ }^{\text {st }}$ Century Economist, (London: RH Business Books, 2017), hlm. 209.

${ }^{47}$ Ha-Joon Chang, Economics: The User's Guide, (London: Penguin Books, 2014), hlm. 324-325.

${ }^{48}$ B. Yandle, M. Vijayaraghavan, M. Bhattarai, "The Environmental Kuznets Curve: A Primer", The Property and Environment Research Center, 2002.

${ }_{49}$ Tejvan Pettinger, "Environmental Kuznets curve", https://www.economicshelp.org/ blog/14337/environment/environmental-kuznets-curve/, diakses tanggal 8 November 2019.
} 
Dari Inpres Moratorium Sawit Hingga Kebijakan Tata Kelola Industri Sawit Presiden Jokowi: Studi Kasus Penerbitan SK Pelepasan Kawasan Hutan PT Hardaya Inti Plantations di Buol, Sulawesi Selatan

dan tingkat polusi yang ada. ${ }^{50}$ Sedangkan, Torras dan Boyce melakukan serangkaian penelitian dengan kesimpulan bahwa kualitas lingkungan meningkat justru ketika pendapatan lebih merata, tingkat literasi tinggi, dan hak-hak sipil serta politik lebih dihormati. Kekuatan masyarakat dan bukan pertumbuhan ekonomi semata, yang justru melindungi kualitas udara dan air setempat. Selain itu perubahan dari industri manufaktur ke industri jasa tidak mengeliminasi pencemaran yang terjadi, melainkan hanya mengubah sumbernya ke negara lain, seringkali negara dunia ketiga, yang memiliki biaya pembuatan pabrik dan upah buruh lebih murah serta dengan peraturan lingkungan yang tidak terlalu ketat. Dengan kata lain, sekelompok orang di suatu tempat akan selalu terkena imbas negatifnya. ${ }^{51}$

Skenario kerusakan lingkungan tersebut bukan tidak mungkin dapat terjadi juga di Indonesia, apabila pendekatan yang digunakan adalah race to the bottom tanpa adanya batasan untuk dampak negatif terhadap sektor sosial dan lingkungan. Hal ini semata-mata demi mengejar pertumbuhan ekonomi dengan mengorbankan lingkungan.

\section{Kesimpulan}

Terdapat tiga kesimpulan yang dapat diambil untuk menjawab rumusan masalah yang diajukan dalam tulisan ini. Pertama, bahwa pelepasan kawasan hutan PT HIP di Buol telah melanggar ketentuan hukum, terutama Inpres Moratorium Sawit, PP 104/2015, Permen LHK 96/2018, dan UU P3H. Kedua, bahwa arah kebijakan industri sawit Presiden Jokowi cenderung condong pada kepentingan ekonomi demi mengejar pertumbuhan ekonomi semata. Ketiga, meskipun sekilas tampak tidak memiliki korelasi, kasus PT HIP dan arah kebijakan industri sawit Presiden Jokowi sebenarnya memiliki benang merah yang sama. Pembiaran dan ketidaktegasan dalam menindak kasus-kasus pelanggaran hukum seperti PT HIP terkait erat dengan kecenderungan pemerintah yang sangat menganakemaskan industri sawit. Terlebih dengan adanya pendekatan race to the bottom yang digunakan, dengan sebisa mungkin menjauhkan industri sawit dari segala macam peraturan yang menghambat, dari mempermudah perizinan hingga keengganan untuk menindak tegas apabila terdapat pelanggaran hukum.

${ }^{50}$ Awudu Abdulai dan Linda Ramcke, "The Impact of Trade and Economic Growth on the Environment: Revisiting the Cross-Country Evidence", Kiel Working Paper, No. 1491, 2009, hlm. 1.

${ }^{51}$ Mariano Torras dan James K. Boyce, "Income, Inequality, and Pollution: A Reassessment of the Environmental Kuznets Curve", Ecological Economics, Vol. 25 No. 2, 1998, hlm. 147-160. 


\section{DAFTAR PUSTAKA}

\section{Peraturan Perundang-undangan}

Indonesia, Kementerian Hukum dan Hak Asasi Manusia, SK Pengesahan No. C2-895.HT.01.01.TH.1996 a.n.

PT Hardaya Inti Plantations.

Peraturan Menteri Pertanian tentang Pedoman Perizinan Usaha Perkebunan, PerMen Pertanian No. 98 Tahun 2013 dan Putusan MK No. 138/PUU-XIII/2015.

Undang-Undang tentang Pencegahan dan Pemberantasan Perusakan Hutan, No. 18 Tahun 2013, LN No. 130, TLN No. 5432, Pasal 92.

Undang-Undang tentang Administrasi Pemerintahan, No. 30 Tahun 2014 LN No. 292, TLN No. 5601, Pasal 66 ayat (4), (5) dan (6).

, Undang-Undang tentang Perkebunan, No. 39 Tahun 2014 LN No. 308, TLN No. 5613, Pasal 15.

- Peraturan Pemerintah tentang Tata Cara Perubahan Peruntukan dan Fungsi Kawasan Hutan, No. 104 Tahun 2015, LN No. 326, TLN No. 5794, Pasal 19 ayat (1).

Menteri Pertanian. Peraturan Menteri Pertanian tentang Sistem Sertifikasi Kelapa Sawit Berkelanjutan Indonesia (Indonesian Sustainable Palm Oil Certification System) No. 11 Tahun 2015.

Instruksi Presiden tentang Penundaan dan Evaluasi Perizinan Perkebunan Kelapa Sawit serta Peningkatan Produktivitas Perkebunan Sawit,
No. 8 Tahun 2018, Diktum Kedua, ayat (1).

Inpres tentang Penundaan dan Evaluasi Perizinan Perkebunan Kelapa Sawit serta Peningkatan Produktivitas Perkebunan Kelapa Sawit, Diktum Kedua, No. 8 Tahun 2018 Nomor 1.

Menteri Lingkungan Hidup dan Kehutanan, Peraturan tentang Tata Cara Pelepasan Kawasan Hutan Produksi yang Dapat Dikonversi, No. 96 Tahun 2018 Pasal 41 ayat (6).

, Peraturan Pemerintah tentang Pelayanan Perizinan Berusaha Terintegrasi Secara Elektronik (Online Single Submission), PP No. 24 Tahun 2018, LN No. 90, TLN No. 6215, Pasal 85 huruf b dan $\mathrm{c}$.

, Menteri Pertanian. Permen Pertanian tentang Tata Cara Perizinan Berusaha Sektor Pertanian, Permen Pertanian No. 5 Tahun 2019 Pasal 8 dan Pasal 13 ayat (1).

\section{Putusan Pengadilan}

Indonesia, Putusan PN Jakarta Pusat No.64/Pid.B/TPK/2012/PN.Jkt.Pst dan Putusan PT DKI Jakarta No. 12/ PID/TKP/2013/PT.DKI. Keduanya telah berkekuatan hukum tetap karena Amran mencabut permohonan kasasinya melalui Penetapan No. 1552 K/Pid.Sus/2013.

\section{Buku}

Badan Pusat Statistik, Statistik Kelapa Sawit Indonesia, (Jakarta: BPS, 2017). 
Dari Inpres Moratorium Sawit Hingga Kebijakan Tata Kelola Industri Sawit Presiden Jokowi: Studi Kasus Penerbitan SK Pelepasan Kawasan Hutan PT Hardaya Inti Plantations di Buol, Sulawesi Selatan

Bryan A. Garner, Black's Law Dictionary 9th ed. (Minnesota: West Publishing Co, 2009).

Ha-Joon Chang, Economics: The User's Guide, (London: Penguin Books, 2014),

Kate Raworth, Doughnut Economics: Seven Ways to Think Like a $21^{\text {st }}$ Century Economist, (London: RH Business Books, 2017).

Norman J. Vig dan Michael E. Kraft, Environmental Policy: New Directions for the Twenty-First Century, (London: SAGE Publications, 2019).

\section{Artikel Jurnal/Media Massa}

Awudu Abdulai dan Linda Ramcke, "The Impact of Trade and Economic Growth on the Environment: Revisiting the Cross-Country Evidence", Kiel Working Paper, No. 1491, 2009.

B. Yandle, M. Vijayaraghavan, M. Bhattarai, "The Environmental Kuznets Curve: A Primer", The Property and Environment Research Center, 2002.

Chandra Gian Asmara, "Jokowi Kesal: Izin Investasi di Vietnam 2 Bulan, RI Tahunan", https://www.cnbcindonesia.com/news/20190904181346-497155/jokowi-kesal-izin-investasidi-vietnam-2-bulan-ri-tahunan, diakses tanggal 8 November 2019.

Dian Maharani, "Hartati Murdaya Divonis 2 Tahun 8 Bulan Penjara" https:// nasiona $1 . \mathrm{kompas}$.com / read/2013/02/04/12134267/Hartati.Murdaya.Divonis.2.Tahun.\%208. Bulan.Penjara.
Francisca Christy Rosana, "Said Didu: Pertamina Dilarang Impor Migas, Rakyat Mati", https://bisnis.tempo. co/read/1142496/bappenas-industri-kelapa-sawit-serap-162-jutatenaga-kerja, diakses 8 November 2019.

Glen S. Krutz, "Getting Around Gridlock: The Effect of Omnibus Utilization on Legislative Productivity", Legislative Studies Quarterly, Vol. 25, No. 4 (November 2000).

Greenomics Indonesia, "80\% areal pelepasan kawasan hutan PT HIP masih berhutan lebat", http://greenomics. org/80-areal-pelepasan-kawasanhutan-pt-hip-masih-berhutan-lebat, diakses tanggal 5 September 2019.

Guhan Subramanian, "The Disappearing Delaware Effect", Journal of Law, Economics, \& Organization, Vol. 20, No. 1, April 2004. https://regional. $\begin{array}{llllllllll}\mathrm{k} & \mathrm{o} & \mathrm{m} & \mathrm{p} & \mathrm{a} & \mathrm{s} & \text {. } & \mathrm{c} & \mathrm{o} & \mathrm{m}\end{array}$ read/2019/01/22/17001771/bupatibuol-geram-klhk-izinkan-9964-hektar-hutan-produksi-jadi-kebunsawit, diakses tanggal 5 September 2019.

Kompas, "Bupati Buol Geram KLHK Izinkan 9.964 Hektar Hutan Produksi Jadi Kebun Sawit".

Luthfia Ayu Anazella, “Apa Itu Omnibus Law, yang Disinggung Jokowi dalam Pidatonya?", https://www. k o m pas.com / t r e n / read/2019/10/22/070600665/apaitu-omnibus-law-yang-disinggungjokowi-dalam-pidatonya-?page=all, 
diakses tanggal 8 November 2019.

Mariano Torras dan James K. Boyce, “Income, Inequality, and Pollution: A Reassessment of the Environmental Kuznets Curve", Ecological Economics, Vol. 25 No. 2, 1998.

Nur Faizah Al Bahriyatul, “KLHK Sebut Administrasi Izin 9.964 ha Kebun Sawit di Buol Sudah Lengkap", https://ekonomi.bisnis.com / read/20190121/99/880899/klhksebut-administrasi-izin-9.964-hakebun-sawit-di-buol-sudah-lengkap, diakses tanggal 5 September 2019.

Sawit Watch, et al. "Shadow Report: Kemana Arah Implementasi Inpres No. 8 Tahun 2018 Berjalan?" disampaikan dalam Diskusi Publik Moratorium Sawit di Jakarta, 17 Mei 2019.

Sawit Watch, et al. "Shadow Report: Kemana Arah Implementasi Inpres No. 8 Tahun 2018 Berjalan?" disampaikan dalam Diskusi Publik Moratorium Sawit di Jakarta, 17 Mei 2019.

Tejvan Pettinger, "Environmental Kuznets curve", https://www.economicshelp.org/blog/14337/environm e $\quad n \quad t /$ environmental-kuznets-curve/ diakses tanggal 8 November 2019.

Viva, "KPK Geram Kementerian Kehutanan Masih Berikan Izin ke Hartati Murdaya" https://www.viva.co.id/ berita/nasional/1115240-kpkgeram-kementerian-kehutananmasih-berikan-izin-ke-hartati-murdaya, diakses tanggal 5 September 2019.

\section{Lain-Lain}

Fadhil Muhammad Indrapraja, "Sertifikasi Minyak Kelapa Sawit Berkelanjutan Sebagai Instrumen Penaatan Hukum Lingkungan: Analisis $\mathrm{Hu}-$ kum Terhadap Indonesian Sustainable Palm Oil, Roundtable on Sustainable Palm Oil, dan Malaysian Sustainable Palm Oil", Skripsi Fakultas Hukum Universitas Indonesia, 2017.

ICEL, “Lembar Fakta Perancangan RUU Perkelapasawitan: Kajian tentang Kebutuhan Pengaturan", 31 Mei 2018.

Indonesia, Ombudsman Sulawesi Tengah, "Ombudsman Temukan Maladministrasi Perkebunan Sawit di Sulteng" https://ombudsman.go. id/perwakilan/news/r/pwk-ombudsman-temukan-maladministrasi-perkebunan-sawit-di-sulteng, dan https://komiu.id/wp-content/ uploads/2019/03/SULAWESITENGAH-BRIEF-OK.pdf.

Rimawan Pradiptyo dan Riawan Tjandra, "Pembebanan Risiko Bisnis Korporasi kepada Sektor Publik: Kajian Terhadap RUU Perkelapasawitan", hlm. 53-54, https://www.tuk.or.id/ wp-content/uploads/2018/02/Kajian-terhadap-RUU-Kepala-Sawit-1. pdf diakses tanggal 8 November 2019. 